\title{
Prognosis in cystic fibrosis treated with continuous flucloxacillin from the neonatal period
}

\author{
L T Weaver, M R Green, K Nicholson, J Mills, M E Heeley, J A Kuzemko, S Austin, \\ G A Gregory, A E W Dux, J A Davis
}

\begin{abstract}
All newborn infants in East Anglia are screened for cystic fibrosis by blood immunoreactive trypsin assay at 7 days. Thirty eight infants with cystic fibrosis were randomised to treatment with either continuous oral flucloxacillin $250 \mathrm{mg} /$ day (group $P, n=18$ ) or with episodic antimicrobials as clinically indicated (group $\mathbf{E}, \mathbf{n}=20$ ). Their progress was monitored from diagnosis to 24 months by a nurse coordinator who visited all infants regularly, at home and in hospital, to collect anthropometric, dietary, clinical, and microbiological data. Mean (range) age of confirmation of diagnosis was $5 \cdot 7$ weeks (1-14 weeks). There was no significant difference in birth weight, genotype, immunoreactive trypsin concentration, neonatal history, symptoms at diagnosis, pancreatic enzyme supplementation, or parental smoking history between the groups. Infants in group $E$ had more frequent cough and a greater number of Staphylococcus aureus isolates than infants in group P. More infants of group $E$ were admitted to hospital, had higher admission rates during the second year (19 $v$ 5), for longer periods (6.4 $v \quad 2.2$ days), despite receiving more than double the number of courses of antibiotics than group $P$ infants (in addition to flucloxacillin). Continuous prophylactic flucloxacillin from early diagnosis of cystic fibrosis is associated with improved clinical progress during the first two years of life.
\end{abstract}

(Arch Dis Child 1994; 70: 84-89)

With the development of methods to identify infants with cystic fibrosis during the neonatal period $^{1}$ opportunities to intervene early in the course of the disease have become available.

The criteria by which the value of a screening programme may be judged require (i) that the disease is an important health problem for the individual and the community, (ii) that its natural history is known, (iii) that it has a latent or asymptomatic phase, (iv) that it may be identified by a suitable screening test, (v) that facilities for diagnosis and treatment are available, and (vi) that its natural history may be favourably modified by early treatment, which (vii) is acceptable and cost effective. ${ }^{2}$

With respect to cystic fibrosis, criteria (i), (iii), (iv), and (v) have been fulfilled: the prevalence of cystic fibrosis in the UK is about $5000,{ }^{3}$ the disease is often not recognised until well into childhood, ${ }^{4}$ it may be accurately identified by neonatal immunoreactive trypsin screening and sweat test, ${ }^{1}$ and facilities for its treatment are widely available. The aim of this study was to address criteria (ii), (vi), and (vii).

Since 1981 all infants born in East Anglia have been screened by blood immunoreactive trypsin assay. We reported the incidence, clinical presentation, biochemical and genotypic characteristics, and early natural history of cystic fibrosis in these children elsewhere. ${ }^{5}$ In this paper we describe the effects of continuous prophylactic antibiotic treatment on the clinical progress of infants born with cystic fibrosis between 1985 and 1990 .

\section{Subjects and methods}

Forty two infants with cystic fibrosis born in East Anglia from a population of neonates identified by screening between April 1985 and November 1989 were studied. The diagnosis of cystic fibrosis was confirmed by clinical examination and sweat testing, as described elsewhere. ${ }^{5}$

After confirmation of diagnosis the parents of each affected child were counselled by the nurse coordinator (KN) who conferred with the local paediatrician and family doctor about clinical management, genetic counselling, and follow up. ${ }^{6}$ With the consent of parents and the approval of the local ethical committees, infants were enrolled in a prospective control trial. Each was randomly assigned to one of two treatment groups.

Eighteen children received continuous prophylactic flucloxacillin $250 \mathrm{mg} /$ day by mouth in divided doses (group P). Twenty children received episodic antimicrobial treatment when clinically indicated at the discretion of their paediatrician and general practitioner (group E). Four infants withdrew from the study soon after diagnosis for personal and/or domestic reasons, leaving 38 subjects who were followed up to two years. 
All infants received chest physiotherapy, pancreatic enzymes, and vitamin supplementation from diagnosis. Choice of feeds was at the discretion of the parents and paediatrician concerned. All infants received a full course of immunisations.

Each child was seen at regular intervals, at home and in hospital, by the full time nurse coordinator, for the collection of domestic, social, nutritional, biochemical, microbiological, radiological, clinical, and anthropometric data. She was continuously available for telephone consultation, to provide parental support, and to coordinate medical and other services. $^{6}$

\section{ANTHROPOMETRY}

Body weight was measured using an electronic balance accurate to $5 \mathrm{~g}$. Body length was measured using a stadiometer accurate to $1 \mathrm{~mm}$. The average values for all children of the group, derived from the individual growth curves of each child, taking into account missing data, were used in the analysis. Body weight and length were expressed as SD or $\mathrm{z}$ scores based on growth standards derived from normal infants and children born in the Cambridge area. ${ }^{7}$

\section{MICROBIOLOGY}

Nose and throat swabs and faecal samples were obtained at regular intervals, and more frequently when the child was unwell, for bacteriological and virological analysis. Respiratory specimens were cultured using standard techniques with emphasis on the identification of Staphylococcus aureus, Streptococcus pneumoniae, Haemophilus influenzae, and Pseudomonas aeruginosa. Stool specimens were cultured on pseudomonas isolation agar after enrichment in acetamide broth. ${ }^{8}$ Standard tissue culture methods were used for virus identification. Electron microscopy of faecal samples was undertaken at the Public Health Laboratory, Ashford, Kent. The number of courses of antibiotics, of at least five days' duration prescribed to children in addition to the flucloxacillin received continuously by group $\mathrm{P}$, was recorded.

\section{RADIOLOGY}

Radiographs of the chest were taken at 1 and at 2 years of age at the hospital regularly attended by each child. They were assessed by one radiologist (AEWD) using the Chrispin-Norman score $^{9}$ and the radiological component of the Shwachman score. ${ }^{10}$

\section{Results}

NEONATAL, CLINICAL, BIOCHEMICAL, GENETIC, SOCIAL, AND NUTRITIONAL DATA

The characteristics of the two groups of children, randomised to receive either continuous flucloxacillin (group P) or episodic antibiotics (group E) are shown in table 1. There was no significant difference in their birth weights,
Table 1 Characteristics of infants studied

\begin{tabular}{|c|c|c|}
\hline & $\begin{array}{l}\text { Group P } \\
(n=18)\end{array}$ & $\begin{array}{l}\text { Group } E \\
(n=20)\end{array}$ \\
\hline $\operatorname{Sex}(\mathbf{M} / \mathbf{F})$ & $10 / 8$ & $10 / 10$ \\
\hline Mean (SE) birth weight (g) & $3240(510)$ & $3360(380$ \\
\hline Mean (SE) gestation (weeks) & 39 (1) & 39 (1) \\
\hline Genotype (delta F508) & $\delta \delta 14, \delta 4$ & $\delta 813, \delta 7$ \\
\hline \multicolumn{3}{|l|}{ Mode of presentation: No (\%) } \\
\hline Screening alone & $13(72)$ & $12(60)$ \\
\hline Meconium ileus & $2(11)$ & $6(30)$ \\
\hline Clinical & $3(17)$ & $2(10)$ \\
\hline \multicolumn{3}{|c|}{ Blood immunoreactive trypsin (IRT, $\mu \mathrm{g} / \mathrm{l})$} \\
\hline Mean (SE) IRT 1 & $116(10)$ & $121(9)$ \\
\hline Mean (SE) IRT 2 & $121(9)$ & $108(9)$ \\
\hline \multicolumn{3}{|l|}{ Sweat test } \\
\hline Mean (SE) osmolality (mmol $/ \mathrm{kg}$ ) & $252(20)$ & $254(18)$ \\
\hline Mean $(\mathrm{SE})$ sodium $(\mathrm{mmol} / \mathrm{l})$ & $96(13)$ & $100(14)$ \\
\hline \multicolumn{3}{|c|}{ Symptoms at diagnostic sweat test: No (\%) } \\
\hline Respiratory & $7(39)$ & $5(25)$ \\
\hline Gastrointestinal & $2(11)$ & $2(10)$ \\
\hline Respiratory + gastrointestinal & $4(22)$ & $5(25)$ \\
\hline None & $5(28)$ & $8(40)$ \\
\hline
\end{tabular}

gestational ages, or sex distributions. All were detected by neonatal immunoreactive trypsin screening: there was no significant difference in mean blood immunoreactive trypsin concentrations measured at 7 days and at 4 weeks. There was no significant difference in the distribution of genotypes between the two groups. Mean (SD) age of diagnostic sweat test was 7 (3) weeks in group P and 5 (3) weeks in group E (not significant). There were no significant differences in mean sweat osmolalities or sodium concentrations between the two groups. At the time of diagnosis $72 \%$ of infants in group $\mathrm{P}$ and $60 \%$ of infants of group $\mathrm{E}$ had symptoms.

The parents of $34(89 \%)$ infants were married or enjoyed stable relationships. Four infants were born of single mothers into one parent families. The mean (SD) age of mothers of group $P$ was 28.4 (4.9) years, and of fathers was $31.6(6.6)$ years. The mean age of mothers of group E was $27 \cdot 8(5 \cdot 7)$ years, and of fathers was $29 \cdot 2(5 \cdot 5)$ years. The social class distribution was equal between the two groups. Cigarettes were smoked in $22 \%$ of households $(n=4)$ of group P (mean of 5 cigarettes/day) and in $33 \%$ of households $(n=6)$ in group $\mathrm{E}$ (mean of 8 cigarettes/day); this difference was not significant.

The proportion of infants breast fed at diagnosis was $53 \%$ of group $\mathrm{P}$ and $16 \%$ of group $\mathrm{E}$, and at six months was $7 \%$ and $0 \%$ respectively. Mixed feeding began within six months in all children and by 12 months $100 \%$ of infants were fully weaned to a solid diet. Pancreatic enzyme supplements were taken by all children from diagnosis.

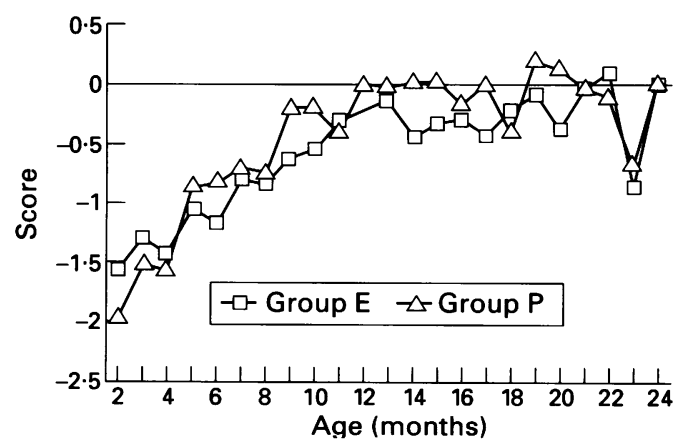

Figure 1 SD (z) scores of weight for age of subjects followed up from birth to 24 months. 


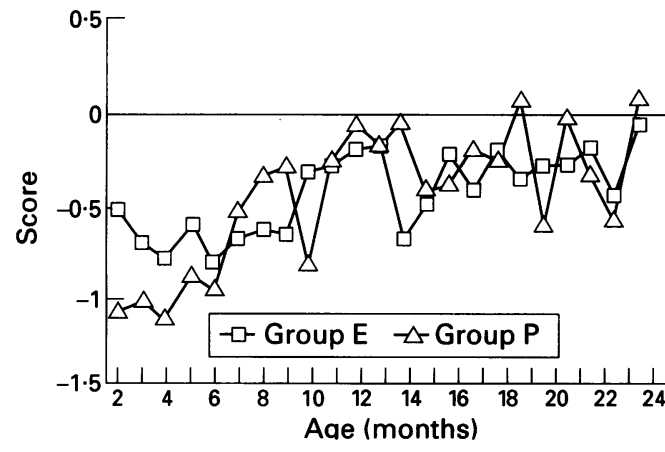

Figure $2 S D(z)$ scores of length for age of subjects followed up from birth to 24 months.

\section{ANTHROPOMETRY}

Figure 1 shows the changes in weight for age $\mathrm{z}$ scores at monthly intervals from diagnosis to two years. Starting with z scores of between 1.5 and 2 SDs below the mean at diagnosis, the weights for age of both groups of infants reached within $0.5 \mathrm{SD}$ of the mean by one year. Figure 2 shows the length for age $\mathrm{z}$ scores which increased from below $-0.5 \mathrm{SD}$ at birth to above $-0.5 \mathrm{SD}$ during the second year. There was no significant difference in the growth curves between the two groups.

\section{MICROBIOLOGY}

The rate of isolation of bacteria from the respiratory and gastrointestinal tracts of children in the two groups are shown in table 2. Specimens positive for $S$ aureus were obtained from the upper respiratory tract of 12 children of group E $(60 \%)$ during 32 infant months compared with positive specimens from three children $(17 \%)$ of group $P$ during six infant months $(\mathrm{p}<0 \cdot 01)$.

$P$ aeruginosa was isolated from four $(22 \%)$ children in group $\mathrm{P}$; from the upper respiratory tract on three $(1 \%)$ infant months (from two (11\%) children); from the stools on 22 $(10 \%)$ infant months (from four $(22 \%)$ children), and from two children out of four isolation was from both stool and respiratory tract.

$P$ aeruginosa was isolated from the upperrespiratory tract of the children in group $\mathrm{E}$ on $10(4 \%)$ infant months (from six (33\%) children), and from the stools on $23(8 \%)$ infant months (from six (33\%) children). In $3 / 9$ children specimens from both upper respiratory tract and stool were positive, in three from the respiratory tract only, and in three from the stool only. The difference in isolation rates of $P$ aeruginosa from the upper respiratory tract between the two groups was not significant $(\mathrm{p}<0 \cdot 1)$.

$H$ influenzae was isolated from seven infants $(39 \%)$ of group P in $10(5 \%)$ infant months.

Table 2 Rate of isolation of bacteria from the upper respiratory and gastrointestinal tracts

\begin{tabular}{|c|c|c|c|c|c|c|c|}
\hline \multirow[b]{3}{*}{ Group } & \multirow[b]{3}{*}{ No } & \multirow{3}{*}{$\begin{array}{l}\% \text { Months } \\
\text { specimens } \\
\text { obtained }\end{array}$} & \multicolumn{5}{|c|}{$\%$ Months specimens positive } \\
\hline & & & \multirow[t]{2}{*}{$S$ aureus } & \multicolumn{2}{|l|}{$P$ aeruginosa } & \multirow[t]{2}{*}{$\mathrm{H}$ influenzae } & \multirow[t]{2}{*}{$S$ pneumoniae } \\
\hline & & & & Respiratory tract & Faeces & & \\
\hline $\begin{array}{l}\mathrm{P} \\
\mathrm{E}\end{array}$ & $\begin{array}{l}18 \\
20\end{array}$ & $\begin{array}{l}66 \\
69\end{array}$ & $\begin{array}{r}2 \\
12\end{array}$ & $\begin{array}{l}1 \\
4\end{array}$ & $\begin{array}{r}10 \\
8\end{array}$ & $\begin{array}{l}5 \\
9\end{array}$ & $\begin{array}{l}8 \\
9\end{array}$ \\
\hline
\end{tabular}

Table 3 Courses of oral antibiotics taken by children

\begin{tabular}{lccccc}
\hline & \multicolumn{2}{c}{ Group $P$ (year) } & & \multicolumn{2}{c}{ Group E (year) } \\
\cline { 2 - 3 } \cline { 6 - 6 } Antibiotic & $1 s t$ & $2 n d$ & & $1 s t$ & $2 n d$ \\
\hline Flucloxacillin or cloxacillin & 9 & 8 & & 43 & 16 \\
Ampicillin or amoxycillin & 23 & 20 & & 38 & 34 \\
Co-amoxiclav & 18 & 19 & & 26 & 27 \\
Ampicillin and flucloxacillin & 1 & 0 & & 16 & 30 \\
Penicillin & 2 & 1 & & 1 & 4 \\
Erythromycin & 3 & 15 & & 20 & 27 \\
Co-trimoxazole & 10 & 5 & & 7 & 18 \\
Cephalosporins & 1 & 1 & & 15 & 8 \\
Ciprofloxacin & 0 & 0 & & 0 & 1 \\
Total & 67 & 69 & & 166 & 165 \\
Courses/child & $3 \cdot 7$ & $3 \cdot 8$ & & $8 \cdot 3$ & $8 \cdot 3$
\end{tabular}

From the children of group E $A$ influenzae was isolated in $25(10 \%)$ infant months, from 10 $(50 \%)$ of the children. The difference between these two isolation rates was not significant.

$S$ pneumoniae was isolated from six children $(33 \%)$ of group P in $18(8 \%)$ infant months, and from $10(50 \%)$ children of group $\mathrm{E}$ in 25 $(9 \%)$ infant months. There was no significant difference in these isolation rates.

Viruses isolated from the respiratory tract included respiratory syncytial virus, adenovirus, Coxsackie $\mathrm{A}$ and $\mathrm{B}$, influenza types $\mathrm{A}$ and $B$, and parainfluenza type 3 . There was no significant difference in the isolation rates between the two groups.

\section{ANTIMICROBIAL TREATMENT}

Children of group E received an average of 8.3 courses of antibiotics per year, and those in group $\mathrm{P}$ an average of 3.7 courses per year. The range of antimicrobial agents prescribed is shown in table 3 . The courses of flucloxacillin received by children of group $P$ represent a doubling of the dose of this antibiotic.

\section{HOSPITAL ADMISSIONS}

The frequency and duration of hospital admissions was lower in the infants and children who received continuous prophylactic antibiotics (group P) than in those who received them episodically (group E) (table 4). The total number of admissions for group $P$ was 23, and for group $E$ was $40(p<0.01)$. This difference was largely in the second year of life, when there were only five child admissions (five children) in group $\mathrm{P}$ compared with 19 child admissions (12 children) in group $\mathrm{E}(\mathrm{p}<0.01)$. The mean (SE) duration of admission of these children during the first year was not significantly different, but in the second year those children receiving continu-

Table 4 Frequency and duration of hospital admissions

\begin{tabular}{|c|c|c|c|}
\hline & Group $P$ & Group $E$ & p Value \\
\hline \multicolumn{4}{|c|}{ Frequency of admissions ${ }^{\star}$} \\
\hline Both years & $23(13)$ & $40(16)$ & $<0.01$ \\
\hline First year & $18(9)$ & 21 (11) & NS \\
\hline Second year & $5(5)$ & $19(12)$ & $<0.01$ \\
\hline \multicolumn{4}{|c|}{ Mean (SE) duration of admissions } \\
\hline Both years & $7 \cdot 3(1 \cdot 2)$ & $10 \cdot 1(2 \cdot 2)$ & NS \\
\hline First year & $8 \cdot 7(1 \cdot 3)$ & $13.4(4.0)$ & NS \\
\hline Second year & $2 \cdot 2(0.9)$ & $6.4(0.9)$ & $<0.01$ \\
\hline
\end{tabular}


Table 5 Chrispin-Norman and Shwachman $\mathrm{x}$ ray scores

\begin{tabular}{|c|c|c|c|c|}
\hline \multirow[b]{2}{*}{ Score } & \multicolumn{2}{|c|}{ Group $P$ (year) } & \multicolumn{2}{|c|}{ Group $E$ (year) } \\
\hline & $1 s t$ & $2 n d$ & $1 s t$ & 2nd \\
\hline \multicolumn{5}{|c|}{ Chrispin-Norman } \\
\hline Median & 0 & 0 & 0 & 0 \\
\hline Mode & 0 & 0 & 0 & 0 \\
\hline Minimum & 0 & 0 & 0 & 0 \\
\hline Maximum & 6 & 4 & 2 & 6 \\
\hline \multicolumn{5}{|l|}{ Shwachman } \\
\hline Median & 25 & 23 & 24 & 20 \\
\hline Mode & 25 & 25 & 25 & 25 \\
\hline Minimum & 15 & 15 & 20 & 10 \\
\hline Maximum & 25 & 25 & 25 & 25 \\
\hline
\end{tabular}

ous flucloxacillin were admitted to hospital for a shorter duration (mean (SE) $2.2(0.9)$ days for group $P$ and $6.4(0.9)$ days for group $E$; $\mathrm{p}<0 \cdot 01$ ).

In over $80 \%$ of cases the reason for admission was for respiratory disease. One child of group E spent 150 days in hospital with respiratory infections (123 days during the first year and 27 days during the second). When he was excluded from the analysis the significance of the difference in hospital admission rates (table 4) remained unchanged. There was no significant relation between a neonatal history of meconium ileus and hospital admission rate; overall those children who had had meconium ileus were admitted to hospital with equal frequency and duration as those who were diagnosed by screening alone. The differences remained significant when between-group differences in smoking and breast feeding were allowed for.

\section{CLINICAL PROGRESS}

The appetites, bowel habits, prevalence of respiratory signs (wheeze, rhonchi, and rib recession) were similar between the two groups at all ages. However, cough was commoner in children of group $E$ than group $P$ from six months, and was significantly so from 18 months onwards $(p<0.01)$.

\section{RADIOLOGY}

The results are shown in table 5 . The majority of children in both groups had normal chest radiographs (Chrispin-Norman score 0, Shwachman score 25) at 1 and at 2 years of age, and there were no significant differences between the groups, nor when scores were compared within groups over time.

\section{Discussion}

In an earlier paper we reported the incidence, clinical presentation, biochemical and genotypic characteristics of 107 infants born in East Anglia between 1981 and $1990 . .^{5}$ Both that and this study were made possible by the neonatal immunoreactive trypsin screening programme. ${ }^{1}$ We describe here the natural history of cystic fibrosis in 38 infants born since 1985, and show that children who receive continuous oral flucloxacillin from diagnosis are less likely to become colonised with $S$ aureus, have fewer respiratory symptoms, and are less likely to be admitted to hospital than those who receive antibiotics as required at the discretion of their doctors.

Population screening of newborns for cystic fibrosis has become established in several parts of the world. ${ }^{1411}$ Retrospective studies have suggested that early diagnosis, and therefore treatment, is beneficial in the long term. ${ }^{4} 1213$ However, the conclusions of these studies have been clouded by changes in treatment during the study period, the lack of proper control groups, and their retrospective design. In a prospective study that compared the outcome of infants identified by screening with those who presented later clinically, ${ }^{14}$ subjects were not properly matched for duration of treatment.

In the randomised, prospective, intervention study reported here we have shown that the natural history of cystic fibrosis may be favourably modified by early treatment, which is acceptable and cost effective, and in so doing that the criteria that justify the implementation of the screening programme ${ }^{2}$ have been fully met.

NEONATAL, CLINICAL, BIOCHEMICAL, AND GENETIC DATA

There were no significant differences in the neonatal characteristics of the two groups (table 1). The distribution of the sexes, gestational ages, birth weights, and genotypes between the two groups was similar. There was a greater number of infants with meconium ileus in group E. However, immunoreactive trypsin screening alone identified $72 \%$ of infants of group $P$ and $60 \%$ of those of group $\mathrm{E}$. The mean age of sweat test was similar in the two groups, and at diagnosis greater than $60 \%$ of infants had symptoms. We have discussed the significance of these data, which do not differ significantly from those of other workers, ${ }^{101215}$ elsewhere. ${ }^{5}$

SOCIAL AND DOMESTIC DATA

There were no significant differences in the social and domestic circumstances of the families of the two groups, and both received equal support from the nurse coordinator.

\section{NUTRITION, FEEDING, AND ANTHROPOMETRY}

Although there were differences in the choice of feeding in early infancy, by six months all infants were receiving a mixed diet, and by one year all were fully weaned to a solid diet.

We took advantage of modern, locally collected growth standards to compare the growth performance of infants with cystic fibrosis with healthy controls. ${ }^{7}$ The weight growth of the children in the two groups with cystic fibrosis was comparable: both showed an increase in weight for age $\mathrm{z}$ scores from between -1.5 and -2 at diagnosis to close to 0 by 12 months. The overall pattern of growth of both groups was similar to that reported elsewhere. ${ }^{16}$ The variation over time between some of the points in the height for age $\mathrm{z}$ scores is an indication of the difficulties of measuring body length 
accurately in wriggling toddlers, bearing in mind that a $\mathrm{z}$ score of $0.5 \mathrm{SD}$ at 12 months represents $1.5 \mathrm{~cm}$, and repeatability of measurements is around $\pm 0.5 \mathrm{~cm}$.

\section{MICROBIOLOGY}

The results show a significant reduction, when prophylactic flucloxacillin is given, in both the number of children colonised and in the number of months in which $S$ aureus was isolated. No flucloxacillin resistant strains of this organism were isolated, and no child receiving continuous treatment developed candidiasis.

There was a positive association between prior or concurrent carriage of $S$ aureus and colonisation with $P$ aeruginosa in patients in group E. Such a pattern has been described in another prospective study. ${ }^{17}$ Colonisation of the respiratory tract with $S$ aureus, which produces a range of cytotoxins, ${ }^{18}$ causes epithelial damage enabling pseudomonas to adhere more easily. Additionally, staphylococcal toxins may also inhibit the action of leucocytes further lowering the patient's ability to resist colonisation of the respiratory tract. ${ }^{16}$ It has also been suggested that viral infection, particularly with respiratory syncytial virus, may predispose to pseudomonas colonisation. Our study does not support this, there being no significant difference in the number or types of viruses isolated from the two groups. Whatever the mechanism, however, it appears that regular oral flucloxacillin while preventing staphylococcal carriage may also inhibit colonisation with $P$ aeruginosa, a major determinant of chronic lung disease in cystic fibrosis. ${ }^{19}$

\section{ANTIMICROBIAL TREATMENT}

Although all children in group $P$ received continuous oral flucloxacillin, many from both groups received, in addition from their family doctors, other antibiotics for respiratory infections (table 3 ). However, children of group $E$ received more than double the number of courses of antibiotics. Those prescribed most frequently were penicillinase resistant or broad spectrum penicillins (flucloxacillin or cloxacillin, ampicillin, amoxycillin, or coamoxiclav).

\section{HOSPITAL ADMISSIONS}

Both frequency and duration of admissions were lower in those children who received continuous flucloxacillin, compared with children in group $\mathrm{E}$ who received antibiotics episodically for an average of $12 \%$ of the year. In over $80 \%$ of cases admissions were for respiratory infections, and even taking into account two children in group $\mathrm{E}$ who had more than four admissions each during the study period (one for a total of 150 days), there was a statistically significant advantage in receiving prophylactic antibiotics.

Blood spot screening has been shown to be cost effective, ${ }^{20}$ and early diagnosis of cystic fibrosis is associated with a reduced hospitalisation rate in the first two years of life, ${ }^{12}$ 13 but this is the first time that the advantage of a specific intervention, made possible by neonatal screening, has been demonstrated. In East Anglia, where the average cost of a day in hospital is around $£ 200$, and of one day of oral flucloxacillin is $33 \mathrm{p}$, such a reduction in hospital admission rate has large economic as well as medical benefits.

\section{CLINICAL PROGRESS AND RADIOLOGY}

The higher frequency of cough in the children who did not receive continuous flucloxacillin (group E) is in accordance with their lower hospital admission rate and staphylococcal isolation rate. However, this was not reflected in the radiology. The absence of a significant difference in chest $x$ ray scores between the two groups, and with advancing age, may be explained in two ways. Chest radiographs are an insensitive way of detecting gradually deteriorating pulmonary function, and all scores were done on radiographs obtained when children were well and out of hospital.

\section{CONCLUSION}

Identification of infants with cystic fibrosis soon after birth offers the opportunity of optimising treatment, of anticipating potential problems, and of counselling families about further pregnancies. A full time nurse coordinator was continuously available to advise the parents of affected children, and her support was greatly appreciated by all families. ${ }^{6}$ The impact of the unexpected news of the diagnosis of a chronic disease requiring life long care may be considerably reduced with the availability of expert advice and treatment, ${ }^{21}$ particularly during the period when the diagnosis is being established. ${ }^{22}$ Counselling and support of parents immediately at diagnosis and for the first year thereafter should be an integral part of any neonatal screening programme.

Nutritional deficits are present from an early age $^{2324}$ and chest infection leads to deteriorating respiratory function. ${ }^{18}$ Interventions therefore should be aimed primarily at ensuring optimal nutrition and preventing pulmonary infection. We have shown that close monitoring and support, with commencement of pancreatic enzyme supplements and physiotherapy from diagnosis, is associated with a return to normal growth centiles by 1 year of age. In addition, continuous oral flucloxacillin treatment is associated with fewer hospital admissions, less clinical morbidity, and lower rates of $S$ aureus isolation than in children who do not receive such antibiotic prophylaxis.

We thank Anthony Heeley, Sue Johnson, Peter Davies, Margaret Fowler, Peter Friend, Sheila Gore, Timothy Cole, and Pamela Howat for their help with this study. It would not have been possible without the collaboration of the consultant paediatricians of East Anglia: Dr Beach (Norwich), Dr Gould (Ipswich), Dr Noble-Jamieson (Bury St Edmunds), Dr Barter and Dr Dossetor (King's Lynn), Dr Roberton (Cambridge), Dr Kuzemko (Peterborough), Dr Challener (Huntingdon), and Dr Stocks (Gorleston). We also thank the parents of the childre studied for their willing cooperation. The Medical Research Council, the Cystic Fibrosis Research Trust, and the Eas Anglia Regional Health Authority provided the financial support which made this study possible. 
1 Heeley AF, Heeley M, King DN, Kuzemko JA, Walsh MP. Screening for cystic fibrosis by dried blood spot trypsin assay. Arch Dis Child 1982; 57: 18-21.

2 Wilson JMG, Jungner G. Principles and practice of screening for disease. Geneva: WHO, 1968.

3 Dodge JA, Goodall J, Geddes D, et al. Cystic fibrosis in the United Kingdom 1977-85: an improving picture. $B M \mathcal{F}$ 1988; 297: 1599-602.

4 Wilcken B, Towns SJ, Mellis CM. Diagnostic delay in cystic fibrosis: lessons from newborn screening. Arch Dis Child 1983; 58: 863-6.

5 Green MR, Weaver LT, Heeley AF, et al. Prospective study of cystic fibrosis identified by neonatal screening. Arch Dis Child 1993; 68: 464-7.

6 Nicholson $K$. The CF nurse-specialist and neonatal screening: child care and research in East Anglia. In: Abingdon: Medicine Group, 1992: 32-8.

7 Paul AA, Black AE, Evans J, Cole TJ, Whitehead RG Breastmilk intake and growth in infants from two to ten months. Fournal of Human Nutrition and Dietetics 1988; 1: 437-50.

8 Kelly NM, Falkiner FR, Keane CT. Acetamide broth for the isolation of pseudomonas aeruginosa for patients with cystic fibrosis. F Clin Microbiol 1983; 17: 159.

9 Chrispin AR, Norman AP. The systematic evaluation of the chest radiograph in cystic fibrosis. Pediatr Radiol 1974; 2: chest radi $101-6$.

10 Shwachman $H$, Kulczycki LL. Long-term study of one hundred and five patients with cystic fibrosis. $A m \mathcal{F}$ Dis Child 1958; 96: 6-15.

11 Roberts G, Stanfield M, Black A, Redmond A. Screening for cystic fibrosis: a four year regional experience. Arch Dis Child 1988; 63: 1438-43.

12 Wilcken B, Chalmers G. Reduced morbidity in patients with cystic fibrosis detected by neonatal screening. Lancet 1985; ii: 1319-21.

13 Dankert-Roelse JE, te Meerman GJ, Martijn A, ten Kate LP, Knol K. Survival and clinical outcome in patients with cystic fibrosis, with or without neonatal screening. $f$ Pediatr 1989; 114: 362-7.
14 Chatfield S, Owen G, Ryley HC, et al. Neonatal screening for cystic fibrosis in Wales and the West Midlands: clinical assessment after five years of screening. Arch Dis Child 1991; 66: 29-33.

15 Wesley AW, Smith PA, Elliott RB. Experience with neonatal screening for cystic fibrosis in New Zealand using measurement of immunoreactive trypsinogen. Australian Paediatric fournal 1989; 25: 151-5.

16 Greer R, Shepherd R, Cleghorn G, Bowling FG, Holt T. Evaluation of growth and changes in body composition following neonatal diagnosis of cystic fibrosis. $\mathscr{f}$ Pediatr Gastroenterol Nutr 1991; 13: 52-8.

17 Abman SH, Ogle JW, Harbeck RJ, Butler-Simon N, Hammond KB, Accurso FJ. Early bacteriologic, immunologic, and clinical courses of young infants with cystic fibrosis identified by neonatal screening. $\mathcal{F}$ Pediatr 1991; 119: 211-7.

18 Easmon CSF, Goodfellow M. Staphylococcus and micrococcus. In: Parker MT, Collier LH, eds. Topley and Wilson's principles of bacteriology, virology and immunity. Vol 2. London: Edward Arnold, 1990: 169-71.

19 Pier GB. Pulmonary disease associated with Pseudomonas aeruginosa in CF: current status of the host-bacterium aeruginosa in CF: current status of the hos
interaction. $\mathcal{F}$ Infect Dis 1985; 151: 575-80.

20 Dauphinais $R$. Cost analysis for screening newborns for cystic fibrosis. Fournal of Clinical Immunoassay 1992; 15: $121-5$.

21 Boland C, Thompson NL. Effects of newborn screening of cystic fibrosis on reported maternal behaviour. Arch Dis Child 1990; 65: 1240-4.

22 Sorenson JR, Harvey LL, Mangione TW, Sepe SJ. Parental response to repeat testing of infants with 'false-positive' results in a newborn screening programme. Pediatrics 1984; 73: 183-7.

23 Reardon MC, Hammond KB, Accurso FJ, et al. Nutritional deficits exist before 2 months of age in some infants with cystic fibrosis identified by screening test. $\mathcal{F}$ Pediatr 1984 ; 105: $271-4$.

24 Sokol RJ, Reardon MV, Accurso FJ, et al. Fat-solublevitamin status during the first year of life in infants with cystic fibrosis identified by screening of newborns. $A m \mathcal{F}$ Clin Nutr 1989; 50: 1064-71. 